University of Nebraska - Lincoln

DigitalCommons@University of Nebraska - Lincoln

Educational Psychology Papers and

Publications

Educational Psychology, Department of

March 1980

\title{
Representation and Process in Reasoning about Logical Relationships
}

David Moshman

University of Nebraska-Lincoln, dmoshman1@unl.edu

Follow this and additional works at: https://digitalcommons.unl.edu/edpsychpapers

Part of the Educational Psychology Commons

Moshman, David, "Representation and Process in Reasoning about Logical Relationships" (1980).

Educational Psychology Papers and Publications. 54.

https://digitalcommons.unl.edu/edpsychpapers/54

This Article is brought to you for free and open access by the Educational Psychology, Department of at DigitalCommons@University of Nebraska - Lincoln. It has been accepted for inclusion in Educational Psychology Papers and Publications by an authorized administrator of DigitalCommons@University of Nebraska - Lincoln. 
Published in The Journal of General Psychology, 103 (1980), pp. 251-262. Copyright (C) 1980 by The Journal Press and Heldref Publications, Helen Dwight Reid Educational Foundation, 1319 Eighteenth Street, NW, Washington, DC 20036-1802. Used by permission. http://www.heldref.org/

An earlier version of this article was presented at the meeting of the Eastern Psychological Association, Washington, March 1978. The author is grateful to J. St. B. T. Evans, Royce Ronning, Rachel Falmagne, and Hank Robb for criticism of previous drafts.

Submitted January 14, 1980.

\title{
Representation and Process in Reasoning about Logical Relationships
}

\author{
David Moshman \\ Department of Educational Psychology \\ University of Nebraska-Lincoln
}

\begin{abstract}
Summary
According to a popular conception of reasoning, the thinker first mentally represents given information and then processes the resulting representations. It is commonly assumed, at least implicitly, that difficulty of the representation step is solely a function of facility with the form and content of the information to be represented, while difficulty of the processing step is solely a function of facility with the operation(s) necessary to meet the task requirements. Within this two-step information processing model, form/content variables and task requirements should thus have an additive effect on problem difficulty. To test this prediction, 72 male students in grades 7, 10, and college were presented with two tasks involving the same set of logical propositions. The effects of both form and content were found to be a function of task. These interactions seem to contradict the notion that form/content and task variables relate exclusively to different steps in reasoning. Theoretical implications of these results for the concepts of representation and process are discussed from information-processing, statistical, and structural perspectives.
\end{abstract}

\section{A. Introduction}

Current conceptions of reasoning distinguish "representation" from "process," and relate these different steps in reasoning (e.g., 4, 9). For a task involving deduction, induction, hypothesis-testing, or problem-solving of any 
sort, it seems reasonable to suppose that the thinker must first mentally represent the relevant data and then process them in accord with the demands of the task. With respect to reasoning about logical relationships, in particular, it is commonly hypothesized that a person first mentally represents (interprets, encodes) the information embedded in the form and content of the relationships, and then processes (operates on) the resulting representation(s) (e.g., 3, 15, 21, 25). The Brée model (3), for example, proposes that subjects test hypothetical implication relationships in Wason's (28) well-known “fourcard task" by first encoding them and then subjecting these encodings to one of three processing strategies.

Two reasonable further postulates, though usually left implicit, seem to underlie most of these information-processing models. The first is that, in any instance of reasoning by any individual, the nature of the representation and the difficulty of the representation step are solely a function of the form and content involved. The second postulate is that the nature of the person's processing and the difficulty of the processing step are solely a function of the operation(s) necessary to meet the task requirements. Thus, for example, the oft-demonstrated effects of form and content on the conclusions subjects reach on reasoning tasks (e.g., 1, 6, 8, 11, 22, 27, 30) would be explained within this two-step information-processing paradigm as due to effects of form and content variables on the difficulty of representing the given information (in step 1) and the nature of those representations.

Thus, the existence of two relatively discrete and ordered steps in processing information, as just described, is a common assumption which serves as the starting point for more specific theories and models regarding the nature of each step (see citations above). Although this simplifying assumption has considerable heuristic value, it has probably been accepted too uncritically. A bit of reflection suggests that the two-step model outlined above is precise enough to have some fairly clear and testable empirical consequences. Specifically, if the model is correct, it follows that the effects of form and content variables would not be a function of task, since such an interaction would indicate either that task requirements are affecting the initial representation of form/content information (contrary to postulate 1), or that form/content variables are affecting the subsequent processing of the representation(s) (contrary to postulate 2). In other words, if form/content variables and task variables relate exclusively to different steps of reasoning, they should have additive (noninteractive) effects on reasoning performance.

Unfortunately, the massive literature on reasoning about logical relationships provides limited information about task differences in the effects of form and content variables because of manipulation of such variables only within the confines of single tasks. Comparison across studies does provide some ev- idence difficult to reconcile with the simple two-step model sketched above. For example, meaningful (as opposed to abstract) content has been shown to facilitate reasoning with conditional relations on the four-card task (e.g., 1, $11,30)$ but to hinder use of conditional premises in deductive reasoning (23) Such comparison across studies is dangerous, however, since it is well established that major differences in reasoning may result from minor variations in wording of presented propositions, task instructions, subject characteristics, and so on (e.g., 26). To allow more rigorous within-study comparisons, each subject in the present experiment did two sorts of tasks, each involving the same set of logical relations varying systematically in form and content. On the basis of the simple model of reasoning outlined above, any effects of form and content should hold across tasks.

\section{B. Method}

\section{Subjects and Procedure}

Twenty-four bright male volunteers in each of grades 7, 10, and college were tested in groups of up to four (total $N=72$ ). The experimenter handed out test booklets and read the instructions aloud, while students read along in their own booklets. After soliciting questions, the experimenter remained present while students continued individually.

\section{Materials}

Each student received a five-page test booklet. The first page presented general instructions and definitions regarding hypotheses, truth, falsity, and proof. On each of the next four pages was a hypothesis to be tested (e.g., of the form If $p$ then $q$ ), followed by eight data descriptions of the form $p \cdot q$ ( $p$ and $q), p \cdot \bar{q}(p$ and not $q), \bar{p} \cdot q, \bar{p} \cdot \bar{q}, q \cdot p, q \cdot \bar{p}, \bar{q} \cdot p$, and $\bar{q} \cdot \bar{p}$, with space next to each data description for the student to indicate whether it proved the hypothesis true, proved it false, or neither. For example, given the hypothesis If a person uses fluoridated toothpaste he will have healthy teeth, the data descriptions would read Albert uses fluoridated toothpaste and has healthy teeth, Bertie uses fluoridated toothpaste and does not have healthy teeth, etc This evaluation task (cf. 5, 12,28) assessed the ability to evaluate the consistency of specific information with a given hypothesis.

Following this part of each page, the student was asked to decide whether it would be better to test the hypothesis by studying $q$ 's or by studying $\bar{q}$ 's (in each case to see whether they are $p$ or $\bar{p}$ ). In the above example, the choice would be between (a) asking patients with healthy teeth whether or not they use fluoridated toothpaste, and (b) asking patients who don't have healthy 
teeth whether or not they use fluoridated toothpaste. The latter is the correct choice, since only people who use fluoridated toothpaste and don't have healthy teeth disprove the hypothesis. Finally, at the bottom of each page, the student was asked to explain the basis for his choice. The essential purpose of this hypothesis-testing problem (derived from Wason's [28] four-card task) is to assess the realization that to test a hypothesis one must seek information that could falsify it.

\section{Design}

The four test pages in each booklet were selected from a set of 16, identical in format but differing in the hypothesis presented. The 16 hypotheses were produced by factorially combining four logical forms (If $p$ then $q$; All $p$ are q; If $p$ then $\bar{q}$; No $p$ are q) with four content areas (toothpaste fluoridation, student performance, canine character, and automotive maintenance (see Table 1).

Since only four of the 16 factorial combinations of form and content were used in each test booklet, and since they had to be arranged in some order,

Table 1

The 16 Hypotheses Used in Constructing the Test Booklets

\begin{tabular}{|c|c|c|}
\hline Content & Form $^{\mathrm{a}}$ & Hypothesis \\
\hline Toothpaste & If $p$ then $\mathrm{q}$ & $\begin{array}{l}\text { If a person uses fluoridated toothpaste he will have healthy } \\
\text { teeth. }\end{array}$ \\
\hline Toothpaste & All $\mathrm{p}$ are $\mathrm{q}$ & All people who use fluoridated toothpaste have healthy teeth. \\
\hline Toothpaste & If $p$ then $\bar{q}$ & If a person uses fluoridated toothpaste he will not get cavities \\
\hline Toothpaste & No $p$ are $q$ & No one who uses fluoridated toothpaste gets cavities. \\
\hline Student & If $p$ then $q$ & If a student works hard in school he will get good grades. \\
\hline Student & All $p$ are $q$ & All students who work hard in school get good grades. \\
\hline Student & If $p$ then $\bar{q}$ & If a student works hard in school he will not fail his courses. \\
\hline Student & No $p$ are $q$ & No student who works hard in school fails his courses. \\
\hline Dog & If $p$ then $q$ & If a dog barks a lot it will be a good watchdog. \\
\hline Dog & All $p$ are $q$ & All dogs that bark a lot make good watchdogs. \\
\hline Dog & If $p$ then $\bar{q}$ & If a dog barks a lot it will not be a good pet. \\
\hline Dog & No $p$ are $q$ & No dog that barks a lot makes a good pet. \\
\hline Engine & If $p$ then $q$ & If an auto engine was just tuned up it will run smoothly. \\
\hline Engine & All $p$ are $q$ & All auto engines that were just tuned up run smoothly. \\
\hline Engine & If $p$ then $\bar{q}$ & $\begin{array}{l}\text { If an auto engine was just tuned up it will not make knocking } \\
\text { sounds. }\end{array}$ \\
\hline Engine & No $p$ are $q$ & $\begin{array}{l}\text { No auto engine that was just tuned up makes knocking } \\
\text { sounds. }\end{array}$ \\
\hline
\end{tabular}

$\overline{\mathrm{a}} \bar{q}=$ not $-q$. the variables form, content, and serial position were necessarily confounded within any test booklet. By constructing the test booklets in groups of four, however, it was possible to use a Greco-Latin square design in which (a) each form, each content area, and of course each serial position appeared exactly once in each text booklet, and (b) the variables form, content, and position were mutually orthogonal within sets of four booklets. Three Greco-Latin squares were randomly selected and used to construct 12 variants of the test booklet, each of which was used by two subjects at each grade level.

\section{Scoring}

To be credited with an "appropriate" (i.e., material implication) evaluation pattern for a given hypothesis, a student had to meet three criteria. First, each of the last four data descriptions was evaluated identically to its logically identical counterpart among the first four (e.g., identical evaluations for $p \cdot q$ and $q \bullet p$ ). Second, the student correctly evaluated as disconfirmatory those data descriptions-and only those data descriptions- that indeed disconfirmed the hypothesis (e.g., for If $p$ then $q, p \bullet \bar{q}$, and $\bar{q} \bullet p$ ). Finally, if any data descriptions were evaluated as conclusively verifying, they were not such as to suggest a biconditional orientation, in which the implication relationship is construed as implying its converse (e.g., identical evaluation of $p \cdot q$ and $\bar{p} \bullet$ $\bar{q})$. Evaluations suggesting biconditionality were systematically identified and disallowed on the basis of previous evidence that this is a common misinterpretation of conditional statements (e.g., 5, 26)

Credit for a "correct" (i.e., falsification-based) hypothesis-testing response for any hypothesis was contingent upon selecting the hypothesis-testing choice that could falsify the hypothesis and providing a falsification explanation. Explanations were considered to reflect falsification provided the student either (a) explicitly indicated that one should test the hypothesis by trying to prove it false, or (6) cited as the crucial consideration a potential datum which, according to his own data evaluations, would prove the hypothesis false. Recoding of 50 randomly selected explanations by an independent coder showed $94 \%$ agreement.

The methodological decision to require both correct judgment and appropriate explanation from the subjects perhaps requires some justification. With respect to the use of explanations, Piaget's (20) work on consciousness suggests that cognizance of one's own mental activity is neither the efficient cause of that activity nor a direct effect or illumination of it, but rather a complex reconstruction on a new level of abstraction. Similarly, Wason and Evans $(29$, p. 150) suggest, among other possibilities, that consciousness and lowerorder cognitive activities may best be viewed not as having a simple cause 
and effect relation (in either direction) but rather as semiautonomous and dialectically interacting processes. There are thus good theoretical and empirica reasons to doubt that $\mathrm{Ss}$ ' introspections provide clear and direct accounts of their actual mental processes. On the other hand, it requires at least as great a leap of inference to infer subjects' mental activities from a limited number of behavioral responses. Van Duyne (27, pp. 93-94), for example, indicated that attention to subjects' verbalizations in addition to their selections on a variant of the four-card task enabled him to avoid many serious misinterpretations. The use of both judgments and explanations in the present study was thus based on the assumption that no methodology yields direct insight into mental processes, and that the best inferences about subjects' reasoning are, therefore, those resting on the broadest and most varied base of data (cf. 14).

\section{Results}

Each subject had an opportunity to show an implication interpretation on each of the four hypotheses he was exposed to. It can be calculated from Table 2 that the proportion of implication evaluations for the entire sample was .41. Based on the null hypothesis that each of a given subject's four evaluations is independent of his others, binomial predictions were calculated for frequencies of $0,1,2,3$, and 4 implication evaluations. Actual frequencies

Table 2

Bivariate Distribution Evaluation Frequency for Implication vs. Falsification Strategy

$\left.\begin{array}{llllllll}\hline \begin{array}{l}\text { Number of } \\ \text { falsification } \\ \text { responses }\end{array} & 0 & 1 & 2 & 3 & 4 & \text { Total } & \text { Exp. }^{\text {a }} \\ \hline 0 & 16 & 11 & 5 & 3 & 2 & 37 & 15.45 \\ 1 & 4 & 1 & 2 & 1 & 1 & 9 & 29.00 \\ 2 & 1 & 5 & 2 & 0 & 1 & 9 & 20.41 \\ 3 & 0 & 2 & 0 & 0 & 1 & 3 & 6.39 \\ 4 & 0 & 1 & 2 & 1 & 10 & 14 & .75\end{array}\right\} 7.14$

${ }^{a}$ Expected frequencies for total based on null hypothesis of independent responses. Combined expectations used as indicated in statistical tests to avoid expected frequencies $<5$. were found to deviate significantly from expectation $\left[\chi^{2}(2)=28.21, p<.001\right]$, and inspection of the marginal totals for evaluation in Table 2 indicates that this was due to a marked trend toward consistency in either applying or not applying an implication interpretation.

A comparable analysis for use of falsification strategy (see Table 2) showed an overall proportion of .32 and a significant trend in the direction of individual consistency $\left.\chi^{2}(2)=63.85, p<.001\right]$. Furthermore, a test of independence on the $3 \times 3$ table formed by collapsing the 1,2, and 3 categories confirmed the significance of the obvious positive relationship between implication evaluation and falsification strategy $\left[\chi^{2}(4)=30.53, p<.001\right]$.

In light of the issues raised previously regarding use of both choices and explanations to infer falsification strategy, it is of interest to look at the relation between them. Ignoring explanations, there were 16 possible patterns $\left(2^{4}\right)$ in choosing one of the two experiments to test each of the four hypotheses. These included consistent choice of potentially falsifying experiments, consistent choice of potentially verifying experiments (cf. 13), consistent choice of the experiment matching a value named in the hypothesis (cf. 4, 5), and 13 miscellaneous patterns of no obvious theoretical import. The consistent falsification pattern accounted for $35 \%$ of the Ss, and no other response pattern accounted for more than $10 \%$. Moreover, Ss consistently choosing the falsification experiment showed a higher proportion of falsification explanations than those not consistently making that choice $\left[.73 v s . .13, \chi^{2}(2)=36.88, p<.001\right]$. Thus, falsification choices and explanations are strongly related and probably reflect real mental processes.

Age differences on these tasks, the nature of immature responses, and the implications of these findings for developmental theory have been discussed elsewhere (17). For present purposes, it is the effects of form and content that are of primary concern. It should be noted, however, that, with one trivial exception, age did not interact with any of the other variables. Thus, the pattern of results discussed below held for each age group separately, as well as for the sample as a whole.

The effects of form are summarized in Table 3. Planned comparisons within this variable involved (a) positive (If $p$ then $q$; All $p$ and $q$ ) $v s$ negative (If $p$ then $\bar{q}$; No $p$ are $q$ ) forms, (b) connective (if . . then) $v s$. quantified (all; no) wordings, and (c) the interaction of a and b. Form significantly affected implication but not falsification responses. The planned comparisons showed the effect of form to be due entirely to a higher proportion of implication evaluations for negative than for positive forms $[F(1,189)=11.15, p$ $<.01]$. Although negation is commonly found to decrease the likelihood of responses conforming to standard logic on various reasoning tasks (e.g., 6, 16, 
Table 3

Proportions and Falsification of Implication Responses on Evaluation Tasks and Hypothesis-Testing as a Function of Form and Content

\begin{tabular}{lcc}
\hline Variable & Evaluation & Hypothesis-testing \\
\hline Form & & .29 \\
$\quad$ If $p$ then $q$ & .35 & .33 \\
If $p$ then not $q$ & .50 & .33 \\
All $p$ are $q$ & .33 & .32 \\
No $p$ are $q$ & .44 & .32 \\
Overall & .41 & \\
Content & & .26 \\
Dog & .28 & .28 \\
Student & .33 & .39 \\
Toothpaste & .42 & .35 \\
Engine & .60 & .32 \\
Overall & .41 & \\
\hline
\end{tabular}

30), the present findings are consistent with evidence (a) that negation of the consequent $(q)$ of an implication may not have this detrimental effect on performance (e.g., 22, 24) and may, in fact, even facilitate it (e.g., 6, 29, 31); and (b) that negative universals ("No") are easier to deal with than positive ("All") universals (18). Perhaps this is because forms such as If $p$ then not $q$ and No $p$ are $q$ emphasize the single falsifying instance (flag), which, depending on the task, may be sufficiently helpful to overcome the additional difficulty due to the extra operation of negation. For present purposes, it is the difference between the two tasks (evaluation vs. hypothesis testing) in the effect of (positive vs. negative) form that is of particular interest and that will be discussed below.

Content area significantly affected both evaluations $[F(3,189)=12.47, p$ $<.001]$ and hypothesis testing $[F(3,189)=3.05, p<.051$. Inspection of Table 3 reveals that the effect of content, like that of form, was a function of task. Specifically, evaluation performance was significantly better with engine content than with any other (each $p<.01$, Duncan's New Multiple Range Test), while for hypothesis testing engine did not differ significantly from any other content area.

\section{Discussion}

The finding that form and content variables significantly affected reasoning performance is neither novel nor surprising. Effects of this sort are already well-documented, as noted above. Further exploration of the particular form and content variables involved in the present research might help elucidate their particular effects, but that would be tangential to the broader concern of this article. The focus of this discussion will not be on these particular variables but rather on the more general implications, for our conceptualization of logical reasoning, of the fact that the effects of form and content on problem difficulty were not consistent across tasks.

One explanation of the form/content $\times$ task interaction is that task factors (in the present study, evaluation vs. hypothesis testing) affect representation of the form/content information (contrary to postulate 1 above). That is, it may be adaptive to represent form/content information differently depending on whether it will later be used for evaluation or hypothesis testing. This is consistent with the contemporary view (e.g., 2) that people do not typically analyze individual sentences in isolation. Rather, they seem to construct representations on the basis not only of sentential information but also of a variety of extralinguistic factors, including task demands.

Another explanation, not inconsistent with the first, is that different forms and content yield representations differing in manipulability (already contrary to postulate 2) and that, moreover, these differences are a function of task. It was hypothesized above, for example, that representations of negative logical forms may emphasize the falsifying instance. This may be particularly facilitative for a task in which differentiation of falsifying and nonfalsifying instances is the main requirement (evaluation) but less so for a task in which the main difficulty is not identifying the falsifying instances but rather recognizing their crucial relevance (hypothesis testing).

Though each of these explanations is quite plausible, reasoning may actually be even more complex than they suggest. Consider the first explanation: How could task factors affect representation of the form/content information before the thinker has begun working on the task (evaluation or hypothesistesting)? But how can work on the task begin until the form/content information of the propositions involved has been represented? As for the second explanation, if differences in the manipulability of the various representations are a function of the processing to be performed on these representations (i.e., the task demands), wouldn't it be adaptive for the thinker to re-represent the information in accord with those task demands? In fact, Falmagne (10) suggests on the basis of three experiments with six- year-olds that even young children are capable of re-representing information in a more adaptive way during the course of processing it.

Thus, it may not be sufficient to reject the assumption that representation difficulties are solely a function of facility with the information to be represented and/or the assumption that later processing of the represented information is solely a function of facility with the operation(s) necessary to meet 
the task demands. Rather, it may be necessary to reject the more basic assumption that representation and process are two successive steps in reasoning. Perhaps reasoning typically involves some preliminary representation of information, followed by tentative processing of that representation, followed by re-representation, followed by further processing, and so on, until the task is completed or abandoned. Even more radically, we may conceptualize representation and processing as proceeding simultaneously throughout the course of reasoning with complex reciprocal interaction between them. Clearly, such reasoning would be far more flexible and adaptive than anything possible within the implicit two-step model that underlies most current theories of logical reasoning.

Of course, even this account remains within the general framework of the information-processing tradition. There are several still more radical alternatives that de-emphasize real-time mental processing of information in their explanations. One such possibility would be a statistical account of the sort proposed by Evans (7), which would make quantitative predictions regarding the probabilities of various responses on the basis of a stochastic model of response tendencies. Another alternative is the structural approach characteristic of the Genevan school (19), which would attempt to explain the individual consistencies in reasoning noted in the present data by postulating underlying structural differences in logical cognition. Interestingly, the information-processing, statistical, and structural paradigms, though inconsistent and even incommensurable in many respects, all find it useful to preserve something akin to the representation/process distinction in spite of its attendant complexities. Thus, Evans' recent work $(6,7)$, including his stochastic model, maintains his longstanding distinction between interpretational and operational factors, though he now (6, p. 305) rejects his earlier (4) assumption that they combine in a simple, additive fashion. Similarly, Piagetian (structural) theory distinguishes figurative and operative aspects of intelligence, though insisting that the two are intricately interdependent.

The ubiquity of the distinction between representation and process suggests that this conceptual dichotomy may be of theoretical value even if the two components are not easily separable steps (cf. 9). Dichotomies are, of course, made to be dissolved, and the present data suggest that all is not well, or at least not as simple as we might have hoped, with the distinction between representation and process. Nevertheless, if we ultimately reject not only the notion of two real-time serial steps in reasoning but the more basic distinction between representation and process, it will probably not be the result of empirical disconfirmation but rather the consequence of constructing a more convincing theoretical alternative.

\section{References}

1. Bracewell, R. J., \& Hidi, S. E. The solution of an inferential problem as a function of stimulus materials. Quart. J. Exper. Psychol., 1974, 26, 480-488.

2. Bransford, J. D. Human Cognition: Learning, Understanding and Remembering Belmont, Calif.: Wadsworth, 1979.

3. Brée, D. S., \& Coppens, G. The difficulty of an implication task. Brit. J. Psychol., 1976, 67, 579-586.

4. Evans, J. St. B. T. On the problems of interpreting reasoning data: Logical and psychological approaches. Cognition, 1972, 1, 373-384.

5. - Interpretation and matching bias in a reasoning task. Quart. J. Exper. Psychol., 1972, 24, 193-199.

6. - Linguistic factors in reasoning. Quart. J. Exper. Psychol., 1977, 29, 297-306.

7. - Towards a statistical theory of reasoning. Quart. J. Exper. Psychol., 1977, 29, 621-635.

8. Evans, J. St. B. T., \& Newstead, S. E. Language and reasoning: A study of temporal factors. Cognition, 1977, 5, 265-283.

9. Falmagne, R. J. Overview: Reasoning, representation, process, and related issues. In R. J. Falmagne (Ed.), Reasoning: Representation and Process. Hillsdale, N. J. Erlbaum, 1975. Pp. 247-264.

10. - Deductive processes in children. In R. J. Falmagne (Ed.), Reasoning: Representation and Process. Hillsdale, N.J.: Erlbaum, 1975. Pp. 175-199.

11. Gilhooley, K. J., \& Falconer, W. A. Concrete and abstract terms and relations in testing a rule. Quart. J. Exper. Psychol., 1974, 26, 355-359.

12. Johnson-Laird, P. N., \& Tagart, J. How implication is understood. Amer. J. Psychol., 1969, 82, 367-373

13. Johnson-Laird, P. N., \& Wason, P. C. A theoretical analysis of insight into a reasoning task. Cogn. Psychol., 1970, 1, 134-148.

14. Larsen, G. Y. Methodology in developmental psychology: An examination of research on Piagetian theory. Child Devel., 1977, 48, 1160-1166.

15. Marcus, S. L., \& Rips, L. J. Conditional reasoning. J. Verb. Learn. \& Verb. Behav., 1979, 18, 199-223.

16. Moshman, D. Consolidation and stage formation in the emergence of formal operations. Devel. Psychol., 1977, 13, 95-100.

17. - Development of formal hypothesis-testing ability. Devel. Psychol., 1979, 15, 104-112.

18. Neimark, E. D., \& Chapman, R. H. Development of the comprehension of logical quantifiers. In R. J. Falmagne (Ed.), Reasoning: Representation and Process. Hillsdale, N.J.: Erlbaum, 1975, 135-151.

19. Piaget, J. Structuralism. New York: Harper \& Row, 1970 
20. —. The Grasp of Consciousness. Cambridge, Mass.: Harvard Univ. Press, 1976.

21. Revlis, R. Syllogistic reasoning: Logical decisions from a complex data base. In R. J. Falmagne (Ed.), Reasoning: Representation and Process. Hillsdale, N.J.: Erlbaum, 1975. Pp. 93-133.

22. Roberge, J. J. Linguistic and psychometric factors in propositional reasoning. Quart. J. Exper. Psychol., 1918, 30, 705-716.

23. Roberge, J. J., \& Antonak, R. F. Effects of familiarity with content on propositional reasoning. J. Gen. Psychol., 1979, 100, 35-41.

24. Roberge, J. J., \& Mason, E. J. Effects of negation on adolescents' class and conditional reasoning abilities. J. Cen. Psychol., 1978, 98, 187-195.

25. Smalley, N. S. Evaluating a rule against possible instances. Brit. J. Psychol., 1974, 65, 293-304.

26. Taplin, J. E., \& Staudenmayer, A. Interpretation of abstract conditional sentences in deductive reasoning. J. Verb. Learn. G Verb. Behav., 1973, 12, 530-542.

27. Van Duyne, P. C. Necessity and contingency in reasoning. Acta Psychol., 1976, 40, $85-101$.

28. Wason, P. C. Reasoning about a rule. Quart. J. Exper. Psychol., 1968, 20, 273-281.

29. Wason, P. C., \& Evans, J. St. B. T. Dud processes in reasoning? Cognition, 1974/75, 3, 141-154.

30. Wason, P. C., \& Johnson-Laird, P. N. Psychology of Reasoning: Structure and Content. Cambridge, Mass.: Harvard Univ. Press, 1912.

31. Wildman, T. M., \& Fletcher, H. J. Developmental increases and decreases in solutions of conditional syllogism problems. Devel. Psychol., 1977, 13, 630-636. 